\title{
Effect of thymidine on activity of trimethoprim and sulphamethoxazole
}

\author{
ANNE STOKES AND R. W. LACEY \\ From the Department of Bacteriology, North Cambridgeshire Hospital, Wisbech, Cambs, UK
}

SUMMARY Thymidine at levels as low as $0.05 \mathrm{mg} / \mathrm{l}$ reduces the activities of sulphamethoxazole and trimethoprim and their combination in vitro. Using a biological assay procedure, levels of thymidine greater than this were interpreted as being present in urine. The addition of sulphamethoxazole and trimethoprim, singly or in combination, to urine obtained from patients with urinary tract infections showed that all the antibacterial effect towards sensitive organisms was due to the trimethoprim component. It is suggested that trimethoprim should replace the combination co-trimoxazole for the treatment of some lower urinary tract infections, and that laboratory media, if they are to resemble the clinical environment, should contain thymidine.

It has been known for many years that the activity of sulphonamides in vitro is affected by the nature of the medium used. The addition of lysed horse red cells to many media has been shown to enhance the activity of sulphonamides and of trimethoprim. This enhancement is due to the neutralisation of antagonists, which comprise mainly thymidine and, to a lesser extent, thymine; the neutralising capacity of horse red cells is due chiefly to the presence of the enzyme thymidine phosphorylase (Bushby, 1973). Accordingly, in recent years, media for sulphonamide and trimethoprim testing have been developed that contain neither thymine nor thymidine (eg, Wellcotest agar, Oxoid diagnostic sensitivity (DST) agar, Oxoid Iso-Sensitest agar), and sensitivity testing using these media does not require the addition of lysed horse red cells to show optimum activity of sulphonamides or trimethoprim.

Sensitivity testing with thymidine-free agar has been thought to reflect the clinical environment, because of the lack of free thymidine present in vivo (Garrod and O'Grady, 1971; Then and Angehrn, 1974). However, these data were derived mainly from analysis of uninfected tissues, and evidence has been accumulating recently that thymidine or other antagonists are present in infected tissue at levels sufficiently high to inactivate some of the antibacterial effect of sulphonamides and trimethoprim in vivo. This evidence has come from three types of observation:

Received for publication 27 July 1977
1. The activities of sulphonamides and trimethoprim were surprisingly poor in an experimental model of urinary infection where there was little evidence of synergy between the drugs (Anderson et al., 1974).

2. Many authors have isolated from purulent lesions bacteria that possess an absolute requirement for thymine or thymidine (Barker et al., 1972; Lacey and Lewis, 1973; Okubadejo and Maskell, 1973; Tanner and Bullen, 1974; Maskell et al., 1976). Such mutants die rapidly in vitro in the absence of thymine or thymidine (Stacey and Simson, 1965; see below), and the isolation of such mutants indicates that levels of thymine or thymidine are present in these patients in amounts sufficient to support the growth of these defective organisms.

3. Maskell et al. (1976) have presented evidence that thymine or thymine-like compounds are present in urine.

In this paper we have assessed the significance of the presence of thymidine in laboratory sensitivity testing media. We also describe the results of experiments performed with the intention of assessing the implications of the presence of thymidine on the treatment of urinary tract infections.

\section{Methods}

DETERMINATION OF MINIMUM INHIBITORY CONCENTRATIONS (MIC) IN AGAR Sulphamethoxazole and trimethoprim were in- 
corporated in doubling dilutions, singly or in combination (in a ratio of 20:1 w/w), into media. Single cell inocula (about 50 bacteria per inoculum) were applied to plates that were then incubated for 20 hours. The end-point was taken as the inhibition of more than $95 \%$ of colony forming units. Synergy was defined as the enhancement, by at least fourfold, of the activity of trimethoprim in the presence of sulphamethoxazole.

\section{MEDIA}

The solid media used were Wellcotest, DST (Oxoid), and Blood Agar Base No. 2 (BAB - Oxoid), with or without the addition of $5 \%(\mathrm{v} / \mathrm{v})$ lysed human or horse red cells. Thymidine was incorporated, generally in doubling dilutions, into some of the media at final levels of between 0.01 and $50 \mathrm{mg} / \mathrm{l}$. Fluid media consisted of peptone water (Oxoid), Wellcotest broth, and urine (see below).

\section{GEL DIFFUSION}

Sulphamethoxazole and trimethoprim were placed in doubling dilutions, singly or in combination (in a ratio of $20: 1 \mathrm{w} / \mathrm{w}$ ), into wells of assay plates seeded with indicator strains. These comprised 10 strains of Staphylococcus aureus sensitive to sulphamethoxazole (MIC less than $20 \mathrm{mg} / \mathrm{l}$ in DST) and trimethoprim (MIC less than $1 \mathrm{mg} / \mathrm{l}$ in DST), and 40 strains resistant to sulphamethoxazole (MIC more than $200 \mathrm{mg} / \mathrm{l}$ ) and sensitive to trimethoprim. These indicator strains were collected from clinical material during 1975-77 and were considered to be epidemiologically distinct isolates. Zones of inhibition were measured using a Leebrook microbiological zone reader after 20 hours' incubation of plates. At least four replicas for each concentration were tested against each organism. Synergy was assessed by the ability of sulphamethoxazole to decrease, by at least fourfold, the trimethoprim concentration necessary to obtain the same zone size. The proportion of sulphamethoxazole to trimethoprim, when in combination, in diffusion testing was always 20:1. When synergy occurred it was evident across a wide range of concentrations of the drugs.

CALCULATION OF THYMIDINE REQUIREMENTS OF THYMIDINE-DEPENDENT MUTANTS

AND THEIR GENERATION TIMES

Three thymidine-dependent strains of Escherichia coli and two of Staph. aureus were monitored in Wellcotest broth, with the addition of various amounts of thymidine. Purified cultures of these organisms were stored at $4^{\circ} \mathrm{C}$ on the surface of BAB containing $5 \mathrm{mg}$ thymidine/l. Colonies were emulsified in saline and then added to $100 \mathrm{ml}$ of
Wellcotest broth in 250-ml conical flasks to give a 을 final concentration of about $10^{5}$ bacteria/ml. The $\underset{\vec{D}}{\vec{*}}$ flasks were incubated, with standard agitation, in a controlled environment produced by a Gallenkamp rotary incubator at $37^{\circ} \mathrm{C}, 100 \mathrm{rpm}$. The cultures were sampled at hourly intervals for six hours by the application of a diluted culture to the surface of $\varrho$ BAB containing $5 \mathrm{mg}$ thymidine/l. Viable counts कs were calculated after 20 hours' incubation of these $\vec{O}$ plates. The doubling times were calculated from the logarithmic phase of growth. A number of colonies were always picked from the viable counts after six hours' incubation to test for the presence of bacteria no longer requiring thymidine. No such revertants were found.

\section{BEHAVIOUR OF ORGANISMS IN URINE}

Urine was obtained from patients during the course of 'routine' investigations and was classified as $\vec{T}$ either non-infected (containing less than $10^{3}$ bac- $\frac{\mathbb{T}}{0}$ teria $/ \mathrm{ml}$ and less than 30 pus cells $/ \mathrm{ml}$ ) or infected (containing more than $10^{5}$ bacteria/ml and more than 100 pus cells $/ \mathrm{ml})$. These urine samples had been stored at $4^{\circ} \mathrm{C}$ for one to two days, were then centrifuged at $3000 \mathrm{~g}$ for 20 minutes to remove coarse debris, filtered through $0.45 \mathrm{~m} \mu$ Millipore filters, and checked for sterility. Each was then tested for the presence of antibacterial agents by the application of $0.2 \mathrm{ml}$ aliquots to wells cut in plates that had been seeded with a fully sensitive strain of $\mathbb{D}$ $E$. coli. Those urines that contained any evidence $\overline{\bar{\sigma}}$ of antibacterial effect were discarded.

Two types of experiment were performed on the urine. One was the addition of strains of $E$. coli ${ }^{\text {? }}$ that required thymidine; this was done in order to assay biologically the amount of free thymidine in urine. In these experiments, the urine was inoculated with a washed suspension of thymidinedependent bacteria to a final density of about $10^{3} / \mathrm{ml}$, and the artificially infected urine was incubated at $37^{\circ} \mathrm{C}$ with standard agitation $(100 \mathrm{rpm})$. Viable counts were performed hourly for six $\frac{T}{0}$ hours.

The second type of experiment was the addition $N$ of sulphamethoxazole, trimethoprim, or the mix- $N$ ture (ratio $1: 1 \mathrm{w} / \mathrm{w}$, see below) to filtered, infected 0 urine together with a suspension of one of three $\omega$ 'normal' strains of $E$. coli (obtained from clinical material). The effect of these agents was monitored as above. These three strains of $E$. coli were sensi- $\mathbb{D}$ tive to the sulphamethoxazole (MIC less than? $20 \mathrm{mg} / \mathrm{l}$ ) and trimethoprim (MIC less than $1 \mathrm{mg} / \mathrm{l}$ ), and each showed marked synergy with the mixture $\frac{\vec{D}}{\mathbb{D}}$ (ratio 20:1 w/w) in thymidine-free agar. The con- $\stackrel{?}{\stackrel{\Omega}{\Phi}}$ centration of antibacterial substances was selected to $\stackrel{D}{\triangle}$ represent active levels commonly found in urine 
after therapeutic doses (Rieder et al, 1974). Thus, the final concentration of both sulphamethoxazole and trimethoprim was $100 \mathrm{mg} / \mathrm{l}$, either singly or in combination.

\section{THYMIDINE-DEPENDENT STRAINS}

Three thymidine-dependent strains of $E$. coli isolated from urinary infections were kindly supplied by Dr R. Maskell, and two thymidine-dependent strains of Staph. aureus were kindly supplied by Mr D. Banner.

\section{DRUGS}

Trimethoprim was obtained from Burroughs Wellcome, sulphamethoxazole from Roche, epicillin from E. R. Squibb, and thymidine and other bases from Koch-Light Laboratories (puriss grade).

\section{Results}

\section{PROPERTIES OF THYMIDINE-REQUIRING}

\section{MUTANTS}

The three strains of E. coli and two of Staph. aureus were confirmed as requiring thymidine for growth by the incorporation of test substances into wells but other nucleic acid bases (guanine, cytosine, adenine, or uracil) could not support growth. Thymine could support the growth of $E$. coli strains but not that of Staph. aureus. This was to be expected as this organism can take up thymidine but not thymine. In view of this, and the observation that thymidine could support growth at lower levels than could thymine, subsequent experiments were performed using thymidine. The incorporation of various amounts of thymidine into solid media (Wellcotest or DST), without the addition of lysed blood, produced normal colonial growth when levels of thymidine between 1 and $5 \mathrm{mg} / \mathrm{l}$ were reached. Above $5 \mathrm{mg} / \mathrm{l}$ there was no further increase in colony size. At lower levels of thymidine the colonies became smaller, and at levels of $0 \cdot 1 \mathrm{mg} / \mathrm{l}$ or less no growth was apparent after 20 hours' incubation at $37^{\circ} \mathrm{C}$.

The precise minimum requirement of thymidine was obtained for each of these strains by the calculation of the effect of various levels of thymidine on the mean generation time. Levels greater than $5.0 \mathrm{mg} / \mathrm{l}$ did not decrease significantly the doubling time but were sometimes inhibitory (Fig. 1; Table 1).

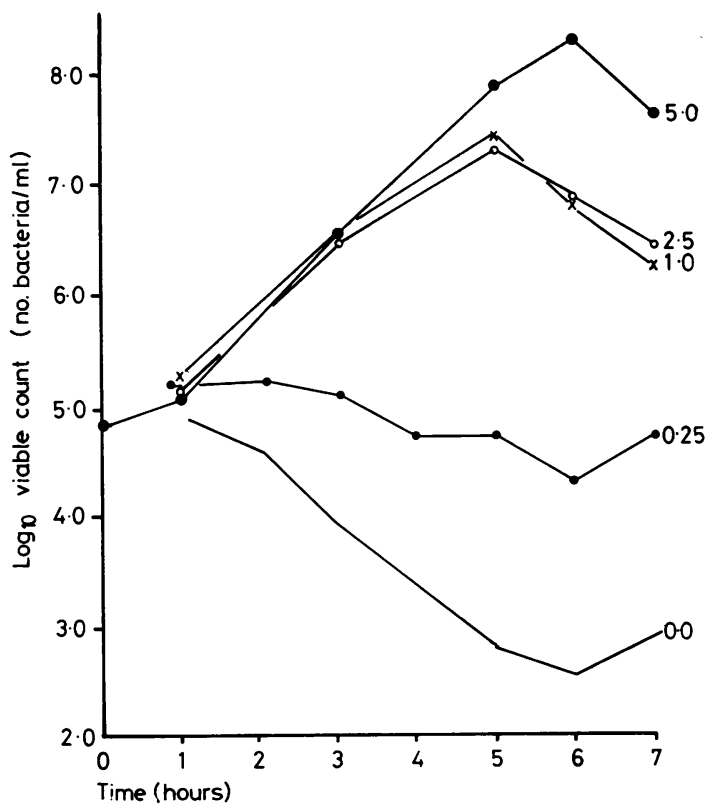

Fig. 1 Growth of a thymidine-requiring strain of Staph. aureus (thy-2) in the presence of various levels of thymidine ( $\mathrm{mg} / \mathrm{l})$ over seven hours.

One strain of $E$. coli $(E$. coli thy-3) showed virtually normal growth in the presence of $1.0 \mathrm{mg}$ thymidine/1; this observation was subsequently used to assay biologically levels of thymidine in urine (see below).

Table 1 Effect of thymidine on generation times (min)* of three thymidine-requiring strains of E. coli and two of Staph. aureus

\begin{tabular}{|c|c|c|c|c|c|}
\hline $\begin{array}{l}\text { Concentration of } \\
\text { thymidine }(\mathrm{mg} / \mathrm{l}) \text { in } \\
\text { Wellcotest broth }\end{array}$ & E. coli thy-1 & E. coli thy-2 & E. coli $t h y-3$ & Staph. aureus $t h y-l$ & Staph. aureus $t h y-2$ \\
\hline $\begin{array}{l}0 \\
0.25 \\
1.0 \\
2.5 \\
5.0 \\
10.0 \\
50.0\end{array}$ & $\begin{array}{l}\text { Dt } \\
\text { NT } \\
54 \cdot 4 \\
20 \cdot 3 \\
23 \cdot 1 \\
23 \cdot 9 \\
26 \cdot 1\end{array}$ & $\begin{array}{l}D \\
D \\
42 \cdot 3 \\
22 \cdot 0 \\
23 \cdot 0 \\
32 \cdot 1 \\
36 \cdot 6\end{array}$ & $\begin{array}{l}D \\
42 \cdot 3 \\
25 \cdot 1 \\
24 \cdot 5 \\
23 \cdot 7 \\
21 \cdot 0 \\
21 \cdot 8\end{array}$ & $\begin{array}{l}\text { D } \\
39 \cdot 9 \\
42 \cdot 8 \\
24 \cdot 7 \\
28 \cdot 8 \\
26 \cdot 2 \\
25 \cdot 4\end{array}$ & $\begin{array}{l}\text { D } \\
\text { NT } \\
64 \cdot 7 \\
\text { NT } \\
30 \cdot 2 \\
28 \cdot 5 \\
28 \cdot 9\end{array}$ \\
\hline
\end{tabular}

* Calculated from the exponential phase of two experiments.

tdenotes reduction in viable bacteria over six hours.

NT - not tested 
Table 2 Effect of thymidine on MIC of suplhamethoxazole and trimethoprim, singly and in combination, for 10 indicator strains of Staph. aureus in various media

\begin{tabular}{|c|c|c|c|c|}
\hline Medium & $\begin{array}{l}\text { MIC (mg/l) without } \\
\text { thymidine (range, if } \\
\text { variation between strains) }\end{array}$ & $\begin{array}{l}\text { Lowest thymidine } \\
\text { concentration to } \\
\text { raise MIC }(\mathrm{mg} / \mathrm{l})\end{array}$ & $\begin{array}{l}\text { Range of fold increase } \\
\text { in MIC at lowest } \\
\text { thymidine level that } \\
\text { raises MIC }\end{array}$ & $\begin{array}{l}\text { MIC }(\mathrm{mg} / \mathrm{l}) \text { in } \\
\text { presence of } 5 \mathrm{mg} / \mathrm{l} \text { thimidine }\end{array}$ \\
\hline $\begin{array}{l}\text { Wellcotest } \\
\text { (no added blood) }\end{array}$ & $\begin{array}{l}0 \cdot 25 \mathrm{~T}, 5 \cdot 0 \mathrm{~S} \\
25-100 \mathrm{~S} \\
2 \cdot 0 \mathrm{~T}\end{array}$ & $\begin{array}{l}0.05 \\
0.05 \\
0.1\end{array}$ & $\begin{array}{l}\text { all }>40 \\
4->10 \\
\text { all }>25\end{array}$ & $\begin{array}{l}>10 \mathrm{~T}, 200 \mathrm{~S} \\
>1000 \mathrm{~S} \\
>50 \mathrm{~T}\end{array}$ \\
\hline $\begin{array}{l}\text { Wellcotest with } \\
5 \% \text { lysed horse } \\
\text { blood }\end{array}$ & $\begin{array}{l}0 \cdot 1 \mathrm{~T}, 2 \cdot 0 \mathrm{~S} \\
25-100 \mathrm{~S} \\
0 \cdot 5-1 \cdot 0 \mathrm{~T}\end{array}$ & $-{ }^{*}$ & - & $\begin{array}{l}0.1 \mathrm{~T}, 2 \cdot 0 \mathrm{~S} \\
25-100 \mathrm{~S} \\
0 \cdot 5-1 \cdot 0 \mathrm{~T}\end{array}$ \\
\hline $\begin{array}{l}\text { DST with } \\
5 \% \text { lysed horse } \\
\text { blood }\end{array}$ & $\begin{array}{l}0.05 \mathrm{~T}, 1.0 \mathrm{~S} \\
0.1 \mathrm{~T}, 2.0 \mathrm{~S} \\
10-25 \mathrm{~S} \\
0.25-0.5 \mathrm{~T}\end{array}$ & - & $\overline{-}$ & $\begin{array}{l}0.05 \mathrm{~T}, 1.0 \mathrm{~S}-0.1 \mathrm{~T}, 2.0 \mathrm{~S} \\
10-25 \mathrm{~S} \\
0.25-0.5 \mathrm{~T}\end{array}$ \\
\hline $\begin{array}{l}\text { Wellcotest with } \\
5 \% \text { lysed human } \\
\text { blood }\end{array}$ & $\begin{array}{l}0.1 \mathrm{~T}, 2.0 \mathrm{~S} \\
10->1000 \mathrm{~S} \\
1.0 \mathrm{~T}\end{array}$ & $\begin{array}{l}0 \cdot 1 \\
0 \cdot 5 \\
0 \cdot 1\end{array}$ & $\begin{array}{l}0-25 \\
0->100 \\
2-50\end{array}$ & $\begin{array}{l}>2.5 \mathrm{~T}, 50 \mathrm{~S} \\
>1000 \mathrm{~S} \\
>50 \mathrm{~T}\end{array}$ \\
\hline $\begin{array}{l}\text { DST with } \\
5 \% \text { lysed human } \\
\text { blood }\end{array}$ & $\begin{array}{l}0.05 \mathrm{~T}, 1.0 \mathrm{~S} \\
10-25 \mathrm{~S} \\
0.5 \mathrm{~T}\end{array}$ & $\begin{array}{l}0.5 \\
0.5 \\
0.5\end{array}$ & $\begin{array}{l}0-5 \\
0-4 \\
0-2\end{array}$ & $\begin{array}{l}>2.5 \mathrm{~T}, 50 \mathrm{~S} \\
>1000 \mathrm{~S} \\
>50 \mathrm{~T}\end{array}$ \\
\hline
\end{tabular}

* Levels of thymidine up to $5 \mathrm{mg} / \mathrm{l} \mathrm{had} \mathrm{no} \mathrm{effect} \mathrm{on} \mathrm{MIC.}$

$\mathrm{S}=$ sulphamethoxazole; $\mathrm{T}=$ trimethoprim

EFFECT OF THYMIDINE ON MIC OF

TRIMETHOPRIM AND SULPHAMETHOXAZOLE

The effect of various levels of thymidine on the MIC was examined in six media-DST or Wellcotest either alone or with the addition of $5 \%$ horse red cells or $5 \%$ human red cells. Ten standard strains of Staph. aureus were used throughout these experiments. These strains were fully sensitive to trimethoprim (MIC less than $1 \mathrm{mg} / \mathrm{l}$ ) and sulphamethoxazole (MIC less than $20 \mathrm{mg} / \mathrm{l}$ ) in DST agar.

The results are presented in Table 2 . In both of the media containing no added red cells, the presence of low levels of thymidine caused a marked increase in the MIC of sulphamethoxazole, trimethoprim, and the combination. This effect was most marked with Wellcotest agar, in which as little as $0 \cdot 05-0 \cdot 1 \mathrm{mg}$ thymidine/l affected the activity of the drugs. At thymidine levels of about $0.05-2.0 \mathrm{mg} / 1$ in Wellcotest agar, colonial appearance was often abnormal, the size becoming progressively larger at a particular drug concentration with increasing levels of thymidine. When thymidine was added (up to $5.0 \mathrm{mg} / \mathrm{l}$ ) to either Wellcotest or DST containing $5 \%$ lysed horse red cells, there was no effect on the MIC for either trimethoprim, sulphamethoxazole, or the combination. Presumably the thymidine is inactivated rapidly and completely by thymidine phosphorylase present in horse red cells (Bushby, 1973). In contrast, in either Wellcotest or
DST agar containing $5 \%$ human red cells, thymidine produced a marked increase in MIC comparable to that occurring without any added red $\stackrel{\square}{\square}$ cells (Table 2). This failure of human red cells to $\overrightarrow{\vec{B}}$ neutralise the antagonistic effect of thymidine is ex-을 plicable by their lack of thymidine phosphorylase.

\section{EFFECT OF MEDIUM ON ACTIVITY OF \\ SULPHAMETHOXAZOLE AND TRIMETHOPRIM} TOWARDS SULPHONAMIDE-RESISTANT

STAPHYLOCOCCI

There have been conflicting views as to whethero there is justification for the use of the combination, co-trimoxazole, against sulphonamide-resistant or-을 ganisms. This uncertainty arises over the observa- $\rightarrow$ tions that some sulphonamide-resistant organisms do not show synergy towards this combination even under optimal conditions. Forty such strains of Staph. aureus (MIC greater than $200 \mathrm{mg} / 1$ in DST) were tested for synergy by MIC methodology inw DST agar containing $5 \%(v / v)$ horse red cells. Undero these optimum conditions, only six strains showedo clearcut synergy, although many showed a very slight decrease in their requirement of sulphame-? thoxazole to produce equivalent inhibitory effect compared with trimethoprim alone. Experiments were then performed with the use of the above sulphonamide sensitive and resistant indicator strains in diffusion testing. Using DST and BABo 
with or without lysed horse blood, the combination of trimethoprim and sulphamethoxazole was always synergistic against the 10 sensitive staphylococci. None of the 40 sulphonamide resistant strains showed synergy in diffusion in either medium. The apparent discrepancy between synergy, as shown by MIC methods and by diffusion testing, is unexplained, but the conflicting views as to whether sulphonamide resistant organisms do or do not show synergy with the combination may, in part, be accounted for by differences in methodology. For the treatment of lower urinary tract infections this debate would seem irrelevant (see below).

EFFECT OF THYMIDINE ON ZONES OF INHIBITION OF SULPHAMETHOXAZOLE AND TRIMETHOPRIM OBTAINED IN DIFFUSION TESTING

The effect of the incorporation of various levels of thymidine into agar in diffusion testing produced a progressive loss of the clarity of the zone, and, in general, the zone was completely lost at levels of thymidine between 1 and $5 \mathrm{mg} / \mathrm{l}$ in Wellcotest agar. Such an effect was difficult to quantify.

\section{GROWTH OF THYMIDINE-DEPENDENT}

STRAINS OF E. COLI IN URINE

Three strains of thymidine-dependent $E$. coli were added to urine from patients with a urinary tract infection (16), or without such infection (3), and viable counts were obtained hourly for six hours. A control $E$. coli was included in each set of experiments so that each urine sample obtained was divided into four, and the behaviour of the thymidine-dependent strains was expressed relative to that of the control. The results for infected and non-infected urine were similar and have therefore been combined. Two of the thymidine-dependent strains ( $E$. coli thy-1 and $E$. coli thy-2) failed to grow over six hours in any of the urines, usually being killed to various degrees. However, with the third strain ( $E$. coli thy-3) growth often occurred, although not as well as that of the control (Fig. 2). The earlier finding that strains $E$. coli thy-1 and $E$. coli thy-2 required $2.5 \mathrm{mg}$ thymidine/1 for normal growth, but that $E$. coli thy-3 required only $1 \mathrm{mg} / 1$, suggests that the amount of thymidine present in the urine is of the order of rather less than $1 \mathrm{mg} / \mathrm{l}$. Since each of these thymidine-requiring strains has been isolated from patients with urinary tract infections, higher levels of thymidine appear to be present in infected tissues than were present in filtered urine. Nevertheless the presence of thymidine at levels of $0.25-1.0 \mathrm{mg} / 1$ could have important effects on the activity of sulphamethoxazole, trimethoprim, or the combination, since it has been

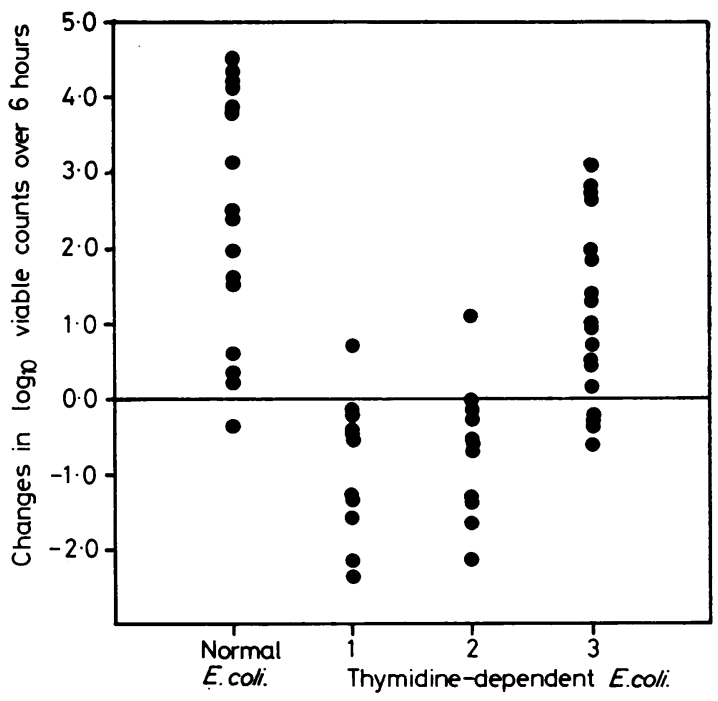

Fig. 2 Behaviour of three thymidine-dependent strains of $\mathrm{E}$. coli in urine. Results expressed as changes in the $\log _{10}$ viable counts between inoculation and the sampling at six hours.

found that such levels can affect the activity of these substances (see above).

GROWTH OF STRAINS OF E. COLI IN

INFECTED URINE IN PRESENCE OF

SULPHAMETHOXAZOLE, TRIMETHOPRIM, OR THE COMBINATION

Infected urine was obtained from 14 patients who had not received antibacterial agents, and a suspension of one of three 'normal' strains of $E$. coli was added to four 4-ml aliquots to give a final density of about $10^{7}$ bacteria $/ \mathrm{ml}$. No antibacterial substance was added to one aliquot (control), $100 \mathrm{mg}$ sulphamethoxazole/1 was added to another, $100 \mathrm{mg}$ trimethoprim/1 to another, and $100 \mathrm{mg}$ of sulphamethoxazole and $100 \mathrm{mg}$ trimethoprim/1 to the last. The growth of the organisms was monitored over six hours in a controlled environment. There were no marked differences between the behaviour of each of the bacteria, so the results were combined (Fig. 3). Growth in the control was comparable to that in urine containing sulphamethoxazole alone; that is, the rather low level of active sulphamethoxazole liberated from the combination appears to be insufficient to cause any inhibition of growth. This was rather surprising as the three strains of $E$. coli were inhibited in DST by about $10 \mathrm{mg} / \mathrm{l}$ of sulphamethoxazole, yet $100 \mathrm{mg} / \mathrm{l}$ of this substance in urine was non-inhibitory. This provides further evidence for the presence of antagonists in urine that are absent from synthetic media. The activity 


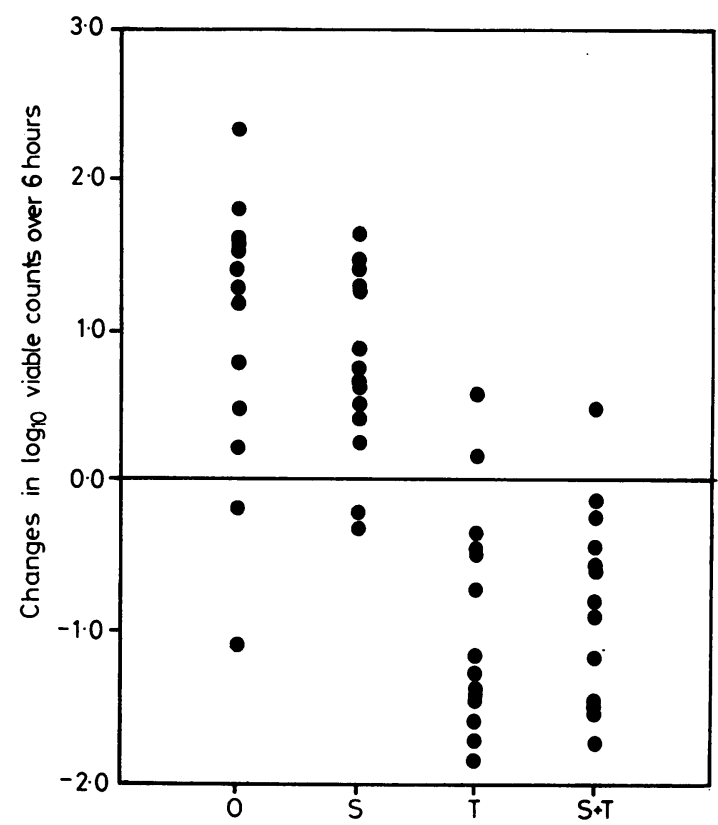

Fig. 3 Activities of sulphamethoxazole $(S)$, trimethoprim $(T)$, and the combination $(S+T)$ in infected urine obtained from patients, filtered, and then inoculated with one of three strains of $\mathrm{E}$. coli (see methods). Results expressed as changes in $\log _{10}$ viable counts between inoculation and the sampling at six hours. There were no significant differences between the control (no antibacterial agent added $(O)$ ) and that containing $100 \mathrm{mg}$ sulphamethoxazole/l $(t=1 \cdot 73$; $P>0 \cdot 1)$. There was also no significant difference between urines containing trimethoprim alone, or both trimethoprim and sulphamethoxazole

$(t=0.74 ; \mathrm{P}>0.2)$.

of trimethoprim appeared identical with that of the combination with sulphamethoxazole (Fig. 3). This was similar to the finding that, in urine obtained from healthy volunteers, there seemed to be no advantage in adding sulphamethoxazole to trimethoprim, and there was certainly no synergy detectable in the urine (Anderson et al., 1974). The activity of trimethoprim and sulphamethoxazole in combination was found in the present study to cause a small reduction in viable bacteria over six hours that was slightly more pronounced than the activity found in volunteer urine (see Anderson et al. (1974)). This difference was presumably due to variations in materials. The activity of the mixture was, however, much less marked than that of a pencillin. Epicillin (an analogue of ampicillin) was added to eight infected urines to a final concentration of $100 \mathrm{mg} / 1$ and produced, over six hours, a reduction in viable bacteria of between $1.5 \times 10^{4}$ and $>8.3 \times 10^{5}$, whereas trimethoprim and sulphamethoxazole in combination produced a maximum reduction of only $4.2 \times 10^{1}$ (Fig. 3 ).

\section{Discussion}

The results presented here show how very low levels $\frac{\widehat{\Phi}}{\sigma}$ of thymidine in culture media can disrupt the activity of sulphamethoxazole and trimethoprim. ${ }^{\infty}$ The presence of significant levels of thymidine are $\overrightarrow{0}$ likely to occur in urine and would be expected to be important during therapy. Maskell et al. (1976) $\vec{\omega}$ have already provided evidence for the presence of thymidine in urine by analysing urine from in-? fected patients using ultraviolet absorption. Our find $-\omega$ ing that urine contains substances able to support the? growth of one thymidine-requiring strain of $E$. coli, $\vec{S}$ and that the synergy between sulphamethoxazole and trimethoprim is disrupted in infected urine, is consistent with the presence of significant levels of $\vec{T}$ thymidine in urine.

The presence of thymidine (and other such antagonists) has two important implications. One is the inference that if sensitivity testing is intended $\vec{\theta}$ to reflect as closely as possible the clinical environment, then a certain amount of available thymidine should be present in media. Wellcotest agar con- 0 tains $10 \mathrm{mg} / \mathrm{l}$ of bases other than thymine or thymidine, so a level of $10 \mathrm{mg} / \mathrm{l}$ thymidine might be an appropriate amount to incorporate into this medium to provide a realistic environment. It would certainly $\mathbb{Q}$ be sufficient to support the growth of thymidine- $\overrightarrow{\vec{A}}$ dependent bacteria. If it is desirable for free thymidine 3 to be present in media, the addition of lysed horse $?$ red cells is obviously inappropriate.

The second implication of these findings is in the treatment of urinary tract infections with combinations of trimethoprim and sulphamethoxazole. $\frac{3}{3}$ If our findings are applicable generally, then we suggest that the presence of the sulphonamide $\frac{3}{3}$ component of this combination has virtually no enhancing effect (that is, synergy) on the activity of ${ }^{\circ}$ trimethoprim. Greenwood and O'Grady (1976) have? used a different approach in the simulation of urinary tract infections by the use of an automatic $N$ 'bladder' with bacteria suspended in Wellcotest ${ }_{N}$ broth. This has the advantage of mechanically resembling micturition, but infected urine will rarely $\omega$ be available in adequate amounts for use as a? medium. However, Greenwood and O'Grady (1976) also considered that the effect of the trimethoprim $\mathbb{\Phi}$ and sulphamethoxazole combination was dominated ${ }^{-}$ by the trimethoprim component. It may well be $\frac{T}{T}$ that in successful therapy with the combination $\frac{\vec{\Phi}}{\mathbb{D}}$ co-trimoxazole all the antibacterial effect in urine is due to the trimethoprim component. If so, 
numerous patients have been exposed unnecessarily to subclinical levels of sulphonamides. A recent report of 13 cases of fatal marrow aplasia associated with the use of co-trimoxazole (Inman, 1977) increases the importance of this possibility. Furthermore, unnecessary exposure of bacteria to sulphamethoxazole has also occurred.

While we consider that the activity of sulphamethoxazole may well be inadequate in vivo, other sulphonamides are present in urine in sufficient amounts to be effective against sulphonamidesensitive organisms. Sulphamethoxazole was the sulphonamide chosen to match trimethoprim on account of its pharmacokinetic properties; it is unfortunate that the active urinary level of this substance is so low, as little as $10 \mathrm{mg} / \mathrm{l}$ being present in the urine of some patients with impaired renal function (Rieder et al., 1974).

In 1974, Anderson et al. stated that 'there is obviously an urgent need for further clinical comparisons of these two agents (the combination and trimethoprim) in order to identify conditions for which the trimethoprim component should be given alone'. It is regrettable that trimethoprim is still not generally available so that such a comparison cannot be made.

The chief conclusions from this work furnish additional evidence for the lack of any advantage in combining sulphamethoxazole with trimethoprim for the treatment of lower urinary tract infections and suggest that thymine and thymidine-free agar may not give a realistic assessment of the activity in vivo of these drugs.

\section{References}

Anderson, J. D., Lacey, R. W., Lewis, E. L., and Sellin, M. A. (1974). Failure to demonstrate an advantage in combining sulphamethoxazole with trimethoprim in an experimental model of urinary infection. Journal of Clinical Pathology, 27, 619-622.

Barker, J., Healing, D., and Hutchison, J. G. P. (1972). Characteristics of some co-trimoxazole-resistant Enterobacteriaceae from infected patients. Journal of Clinical Pathology, 25, 1086-1088.

Bushby, S. R. M. (1973). Sensitivity testing with trimethoprim/sulphamethoxazole. Medical Journal of Australia. 1, 10-18. (Special Supplement, No. 2).

Garrod, L. P., and O'Grady, F. (1971). Antibiotics and Chemotherapy, pp. 42-52. Livingstone, Edinburgh.

Greenwood, D., and O'Grady, F. (1976). Activity and interaction of trimethoprim and sulphamethoxazole against Escherichia coli. Journal of Clinical Pathology, 29, 162-166.

Inman, W. H. W. (1977). Study of fatal marrow depression with special reference to phenylbutazone and oxyphenbutazone. British Medical Journal, 1, 15001505.

Lacey, R. W., and Lewis, E. (1973). Is co-trimoxazole bactericidal in sputum? (Letter). British Medical Journal, 4, 165.

Maskell, R., Okubadejo, O. A., and Payne, R. H. (1976). Thymine-requiring bacteria associated with cotrimoxazole therapy. Lancet, 1, 834-835.

Okubadejo, O. A., and Maskell, R. M. (1973). Thymine requiring mutants of proteus mirabilis selected by cotrimoxazole in vivo. Journal of General Microbiology, 77, 533-535.

Rieder, J., Schwartz, D. E., Fernex, M., Bergen, T., Brodwell, E. K., Blumberg, H., Cottier, P., and Scheithin, W. (1974). Pharmacokinetics of the antibacterial combination sulphamethoxazole plus trimethoprim in patients with normal or impaired kidney function. Antibiotics and Chemotherapy, 18, 148-198.

Stacey, K. A., and Simson, E. (1965). Improved method for the isolation of thymine-requiring mutants of Escherichia coli. Journal of Bacteriology, 90, 554-555.

Then, R., and Angehrn, P. (1974). Co-trimoxazole resistance (Letter). British Medical Journal, 1, 78-79. 